\title{
Bilateral chylothorax associated with osteophytes in an elderly patient
}

\author{
Kohei Horiuchi, ${ }^{\oplus}$ Takanori Asakura, ${ }^{1,2}$ Shinji Sakaguchi, ${ }^{1}$ Fumitake Saito ${ }^{1}$
}

'Department of Pulmonary Medicine, Eiju General Hospital, Taito-ku, Japan

${ }^{2}$ Division of Pulmonary Medicine, Department of Medicine, Keio University School of Medicine, Shinjuku-ku, Japan

\section{Correspondence to}

Dr Kohei Horiuchi, kohei.horiuchi17@gmail.com

Accepted 15 March 2019

\section{DESCRIPTION}

A healthy 71-year-old man presented to our hospital with progressive dyspnoea. Three months prior, he had fallen from a bicycle; however, he had no injury and continued with regular activities. Physical examination revealed decreased breath sounds bilaterally but was otherwise unremarkable. Chest radiography showed bilateral pleural effusion (figure 1A), which occupied half of each hemithorax, as observed in a CT scan. Bilateral thoracentesis fluid appeared milky (figure 1B); fluid analysis showed high triglyceride (right, $1881 \mathrm{mg} / \mathrm{dL}$; left, $1545 \mathrm{mg} / \mathrm{dL}$ ) and low cholesterol (right, $85 \mathrm{mg} / \mathrm{dL}$; left, $83 \mathrm{mg} / \mathrm{dL}$ ) levels, indicating chylothorax. Fluid cytology showed no evidence of malignancy. Treatment included bilateral thoracic drainage, octreotide injection and total parenteral nutrition. CT after chest tube insertion revealed fluid accumulation at the posterior mediastinum (figure 1C), with no evidence of malignancy or injuries. Lymphangiography revealed the location of extravasation as consistent with osteophytes at the second and third lumbar vertebrae (figure 2). The patient improved after 3 weeks of conservative treatment and was followed up without relapse for 10 months.

Chylothorax has non-traumatic causes, including malignancy, sarcoidosis, other benign diseases and traumatic causes comprising iatrogenic and non-iatrogenic events. ${ }^{1}$ Chylothorax may occur rarely due

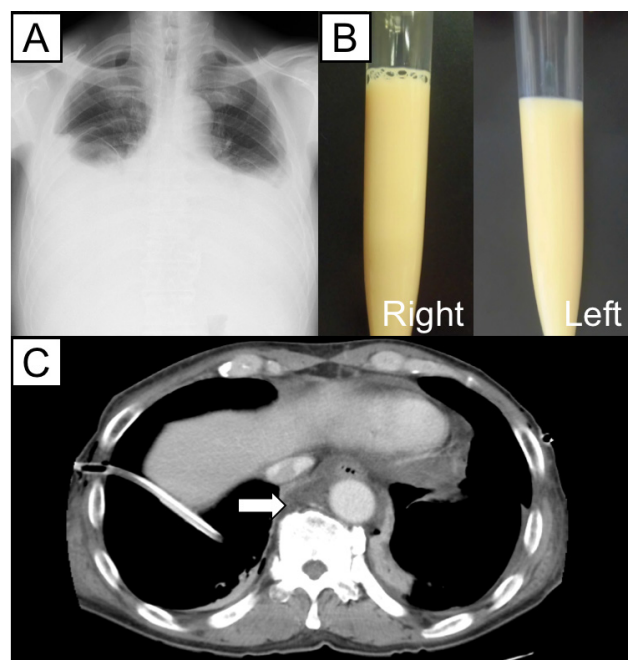

Figure 1 Chest imaging on admission showed bilateral pleural effusion (A). Bilateral pleural fluid exhibited a milky appearance (B). CT showed fluid accumulation (arrow) at the posterior mediastinum after treatment with bilateral thoracic drainage (C).

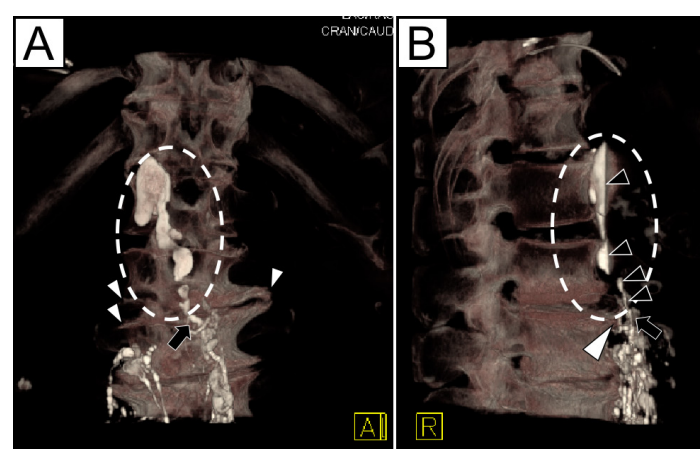

Figure 2 Three-dimensional lymphangiography imaging ( $A$, coronal; $B$, sagittal) revealed extravasation (white circle) with niveau formation ( $B$, black arrowhead) consistent with osteophyte at the second and third lumber vertebra (white arrowheads). Point of leakage is shown ( $A$ and $B$, black arrows).

to non-surgical blunt trauma to lymphatic vessels; the pathogenesis may involve spinal hyperextension, direct injury by vertebral fracture or direct cut by diaphragmatic crura. ${ }^{2}$ Our case is unique in that lymphangiography revealed the location of lymphatic leakage consistent with osteophytes. Since there was no evidence of non-traumatic aetiology and fractures of ribs or vertebrae that could damage the lymphatic vessel, we presume that the lymphatic leakage was due to osteophytes damaging the lymphatic vessel by minor blunt trauma. Consequently, the leakage passed through the posterior mediastinum and spread bilaterally to the thoracic cavity. There is no consensus on the management of chylothorax; conservative treatment includes thoracic drainage, octreotide injection and total parenteral nutrition, but thoracic duct ligation is considered for refractory chylothorax. In this case, lymphangiography played an important role as it revealed lymphatic leakage below the diaphragm. Without lymphangiography, we may have attempted thoracic duct ligation, which would have failed because it is performed above the diaphragm.

In conclusion, we encountered a patient with bilateral chylothorax associated with osteophytes 3 months after blunt trauma. In patients with

\section{Learning points}

- Osteophytes may damage lymphatic vessels by minor blunt trauma and cause chylothorax.

- Chylothorax associated with osteophytes at the lumbar vertebral level maybe a contraindication for thoracic duct ligation. 
chylothorax, physicians should identify osteophytes in the vertebra that could damage lymphatic vessels, because thoracic duct ligation may be contraindicated in such cases.

Contributors $\mathrm{KH}$, SS and FS provided patient care and designed the study. $\mathrm{KH}$ TA and SS wrote the initial draft of the manuscript. FS supervised the study and suggested critical revisions regarding important intellectual content. All authors approved the final version as submitted to the journal.

Funding The authors have not declared a specific grant for this research from any funding agency in the public, commercial or not-for-profit sectors.
Competing interests None declared.

Patient consent for publication Obtained.

Provenance and peer review Not commissioned; externally peer reviewed.

\section{REFERENCES}

1 McGrath EE, Blades Z, Anderson PB. Chylothorax: aetiology, diagnosis and therapeutic options. Respir Med 2010;104:1-8.

2 Pillay TG, Singh B. A review of traumatic chylothorax. Injury 2016;47:545-50.

3 McCormick J. 3rd, Henderson SO. Blunt trauma-induced bilateral chylothorax. Am J Emerg Med 1999;17:302-4.

Copyright 2019 BMJ Publishing Group. All rights reserved. For permission to reuse any of this content visit

https://www.bmj.com/company/products-services/rights-and-licensing/permissions/

BMJ Case Report Fellows may re-use this article for personal use and teaching without any further permission.

Become a Fellow of BMJ Case Reports today and you can:

- Submit as many cases as you like

- Enjoy fast sympathetic peer review and rapid publication of accepted articles

- Access all the published articles

Re-use any of the published material for personal use and teaching without further permission

For information on Institutional Fellowships contact consortiasales@bmjgroup.com

Visit casereports.bmj.com for more articles like this and to become a Fellow 